\title{
The Rate of Spondylodiscitis in Patients with Lomber Discectomy Using Single Dose Prophylactic Antibiotics
}

\author{
Furkan Diren ${ }^{1}$ (D), Mehmet Bülent Önal² (D), Halil $\mathrm{Can}^{3}$ (D), Atilla Kırcelli4 (i) \\ ${ }^{1}$ Department of Brain and Nerve Surgery, University of Health Sciences Gaziosmanpaşa Taksim Training and Research Hospital, İstanbul, Turkey \\ ${ }^{2}$ Acıbadem Mehmet Ali Aydınlar University Health Occupation High-School, İstanbul, Turkey \\ ${ }^{3}$ Clinic of Brain and Nerve Surgery, Biruni University Medicine Hospital, İstanbul, Turkey \\ ${ }^{4} \mathrm{Clinic}$ of Brain and Nerve Surgery, Başkent University İstanbul Research Hospital, İstanbul, Turkey
}

Cite this article as: Diren F, Can H, Önal MB, Kırcelli A. The Rate of Spondylodiscitis in Patients with Lomber Discectomy Using Single Dose Prophylactic Antibiotics. JAREM 2019; 9(Supplement 1): S1-6.

\begin{abstract}
Objective: The incidence of spondylodiscitis following lumbar discectomy has been reported to range between $0.1 \%$ and $18.8 \%$ by various authors. The most common pathogen is Staphylococcus aureus.

Methods: We collected retrospectively the medical records of 1154 patients who had the single-level or two-level disc herniation and were operated for lumbar microdiscectomy between 2007 and 2015 in our hospital. Of them, 554 were female and 600 were male. A total of 1062 patients underwent single-level, 91-level two-level lumbar microdiscectomy. All of these patients were given prophylactic single-dose cefazoline sodium during anesthesia in accordance with the recommendations of the surgical antimicrobial prophylaxis guidelines. Spondylodiscitis developed in 12 patients (1.03\%). The comorbidities in patients treated for spondylodiscitis, isolated pathogens, antibiotic susceptibility, antibiotics used, and hospital stay were recorded.

Results: Of the 12 patients, 7 were female and 5 were male. The mean age was $45.75 \pm 14.16$ years. Eleven patients underwent single-level, and 1 two-level lumbar microdiscectomy procedures. 5 patients underwent discectomy from L4-5 and 8 patients from L5-S1 levels. Staphylococcus aureus was present in 3 patients (25\%), Staphylococcus epidermidis in 4 (33\%), Escherichia coli in 3 (25\%), and 2 patients had no detected pathogens. The mean duration of hospital stay was $29.45 \pm 3.98$ days, and in patients without spondylodiscitis, it was $1.99 \pm 0.81$ days, meaning that there was a significant difference between these groups $(p=0.0001)$.

Conclusion: Although most surgeons tend to maintain antibiotic prophylaxis postoperatively or during the hospitalization period, our study found that a single dose prophylactic antibiotic administered during anesthesia induction did not increase the rate of spondylodiscitis, compared to the results found in the medical literature.
\end{abstract}

Keywords: Spondylodiscitis, lumbar microdiscectomy, Staphylococcus aureus

\section{INTRODUCTION}

Although iatrogenic spondylodiscitis seen after lumbar disc surgery is very rare, its incidence has been reported to be between $0.1 \%$ and $3 \%$ by many different authors (1-15). Most studies on this subject are based on a retrospective case series. It is difficult to determine the true incidence of spondylodiscitis. It can be observed after iatrogenic spondylodiscitis, discography, chemonucleosis, intradiscal procedures (e.g., percutaneous laser disc decompression and nucleoplasty), and lumbar disc herniation surgery. Although the rate of infection in conventional discectomy is between $0.7 \%$ and $2.8 \%$, there are authors who claim that this rate is higher in microdiscectomy (16). In addition, lumbar puncture, myelography, and chemical sympathectomy may cause distance contamination and thus cause discitis.
With respect to the development of spondylodiscitis, it is debated whether the disc level is due to intraoperative contamination, adjacent organs, or hematogenous spread. The most common pathogen is Staphylococcus aureus. The diagnosis of spondylodiscitis is made by clinical laboratory and magnetic resonance imaging (MRI).

In some studies, despite adequate treatment for postoperative spondylodiscitis, the percentage of patients who could not continue under the former working conditions was reported to be $66.7 \%$ and $87.5 \%(9,11,17)$, but in a large series of patients with 7493 operations and 90 spondylodiscitis, only $44.6 \%$ have returned to their former occupations (18). Owing to this negative result of postoperative spondylodiscitis, prophylaxis is clearly important. It has been found to be used for perioperative intra-

ORCID IDs of the authors: F.D. 0000-0001-6169-9722; M.B.O. 0000-0003-0563-3221; H.C. 0000-0002-6792-9987; A.K. 0000-0003-2109-1274. 
venous antibiotics or for cleaning the disc area by irrigation with antiseptic or antibiotic solution, but postoperative spondylodiscitis has been significantly reduced $(10,13)$. The aim of the present study was to describe the incidence of spondylodiscitis in patients who underwent single dose antibiotic prophylaxis under anesthesia induction and did not use prophylactic antibiotics in the postoperative period.

\section{METHODS}

\section{Patient Population and Surgical Technique}

The medical records of 1154 patients who were operated for single-level or two-level lumbar disc hernia between 2007 and 2015 in our hospital were retrospectively examined. The study included 554 female and 600 male patients. Discectomy was performed in 1062 patients with single-level lumbar microsurgery and 91 patients with two-level lumbar microsurgery (Table

Table 1. Demographic factors

\begin{tabular}{|l|c|}
\hline Age (year, average \pm SD) & $43.05 \pm 12.58$ \\
\hline Gender $(n, \%)$ & \\
\hline Male & $600(52)$ \\
\hline Female & $554(48)$ \\
\hline Level $(n, \%)$ & \\
\hline L2-3 & $110(8.8)$ \\
\hline L3-4 & $140(11.2)$ \\
\hline L4-5 & $444(35.6)$ \\
\hline L5-S1 & $505(44.4)$ \\
\hline Multilevel ( $\mathbf{n}, \%)$ & 91 \\
\hline Hospitalization duration (day, average \pm SD) & $1.99 \pm 0.81$ \\
\hline SD: standard deviation & \\
\hline
\end{tabular}

1). All patients were operated in the operating room in the prone position under general anesthesia after sterile drape procedures. All patients underwent discectomy under a microscope undergoing hemiparsiel laminectomy, foraminotomy, and flavectomy. Hemostasis at the operation site was carefully looked out for cartilage end plates were not damaged, and disc distance was not curated, but disc distances were irrigated with gentamicin serum at the end of the operation. All patients were administered a single dose of $1 \mathrm{~g}$ intramuscular cefazolin sodium antibiotic prophylaxis during anesthesia induction according to the recommendations of the surgical antibiotic prophylaxis guidelines. Spondylodiscitis developed in 12 (1.03\%) patients during the 8-year follow-up period. Comorbidities, isolated pathogens, antibiotic susceptibility, antibiotics used, and duration of hospitalization were noted in a patient who developed spondylodiscitis.

The study was carried out in accordance with the criteria of the Declaration of Helsinki.

\section{Diagnosis of Spondylodiscitis in the Postoperative Period}

All patients were recorded by subtracting erythrocyte sedimentation rate (ESR) and complete blood count from preoperative tests. The first controls after discharge were performed on day 15. MRI was performed on patients who referred to us once more with increased low back pain and/or leg pain in the postoperative period. In the control MRI of patients with ESR, an increase in white blood cell count and C-reactive protein (CRP); the observation of hypointensity of the spine adjacent to the operated disc on T1-weighted examinations, hyperintensity in T2-weighted sections, and contrast retention on both end plates in contrasted sections; and a decrease of the disc height, when supported with clinical complaints, as well as laboratory findings, lead to the diagnosis of spondylodiscitis, and these patients were hospitalized. After admission of these patients, biopsy was performed from the disc distance percutaneously, tissue cultures were studied, and pathogens were tried to be detected. Antibiotic that

Table 2. Summary of patients who developed spondylodiscitis

\begin{tabular}{|l|l|l|l|l|c|}
\hline Patient no. & Gender & Age & Level & Pathogen & Referred at week \\
\hline 1 & Female & 65 & L5-S1 & Staphylococcus aureus & 10 \\
\hline 2 & Male & 40 & L5-S1 & Staphylococcus epidermidis & 6 \\
\hline 3 & Female & 39 & L4-5, L5-S1 & Staphylococcus epidermidis & 6 \\
\hline 4 & Female & 23 & L5-S1 & Escherichia coli & 4 \\
\hline 5 & Male & 61 & L5-S1 & No growth & 4 \\
\hline 6 & Female & 49 & L5-S1 & Staphylococcus aureus & 10 \\
\hline 7 & Male & 26 & L4-5 & Escherichia coli & 14 \\
\hline 8 & Female & 41 & L5-S1 & Escherichia coli & 13 \\
\hline 9 & Female & 38 & L5-S1 & Staphylococcus aureus & 2 \\
\hline 10 & Male & 58 & L5-S1 & No growth & 13 \\
\hline 11 & Female & 44 & L5-S1 & Staphylococcus epidermidis & 13 \\
\hline 12 & Female & 65 & L5-S1 & Staphylococcus epidermidis & 10 \\
\hline
\end{tabular}



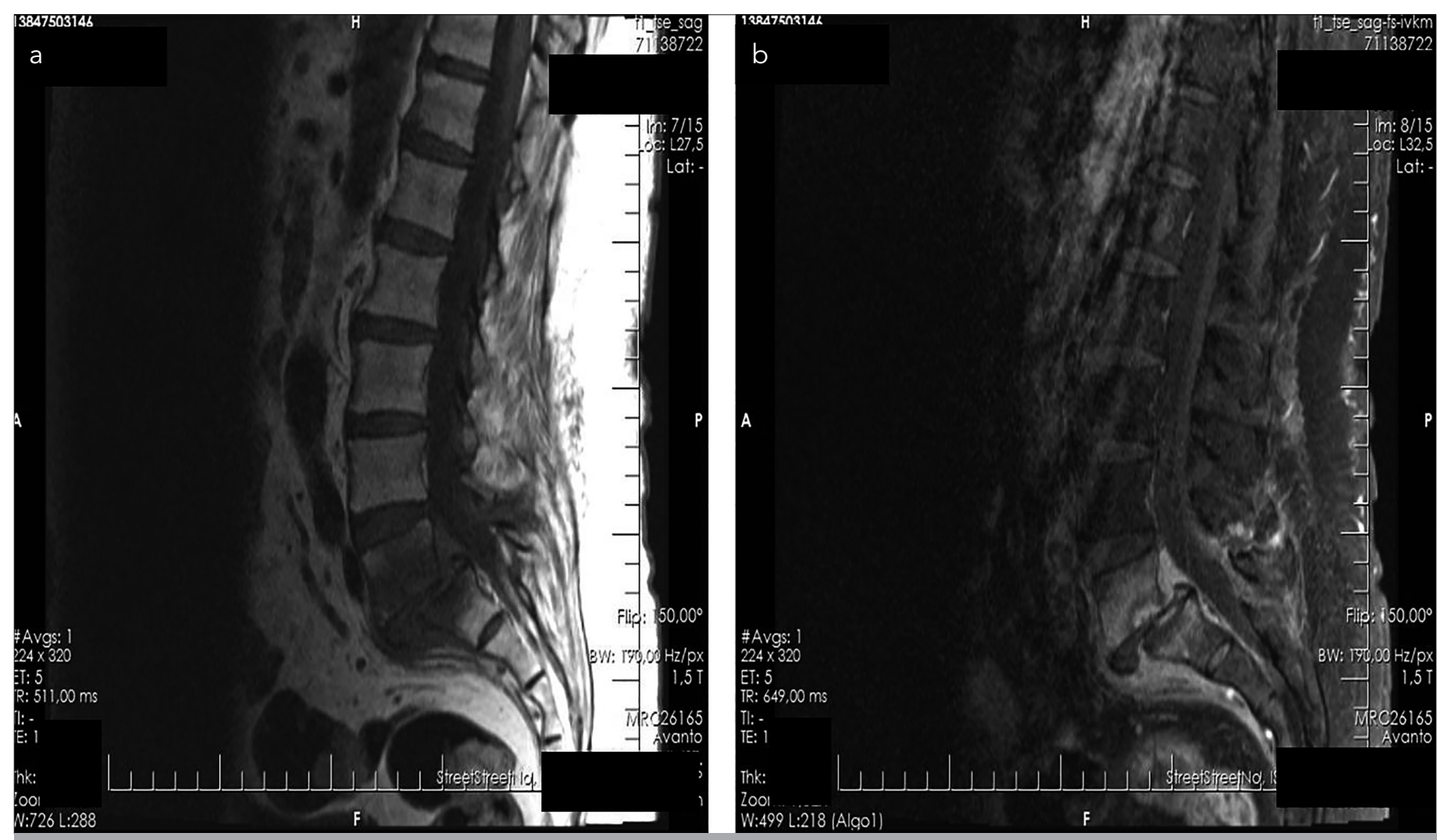

Figure 1. a, b. Image of L5-S1 level of discitis on T1W sagittal MRI (a) and image of L5-S1 level of discitis on T1W sagittal MRI with contrast (b)

was sensitive to the patients with pathogen and antibiogram was given as a result of infectious diseases consultation.

\section{RESULTS}

Spondylodiscitis developed in 12 (1.03\%) out of 1154 patients who were operated in our hospital for lumbar disc hernia and who underwent antibiotic prophylaxis only during anesthesia induction. The average length of hospitalization of all patients at the time of operation was $1.99 \pm 0.81$ days. Of the 12 patients diagnosed with spondylodiscitis, 7 were female, and 5 were male. The average age of these patients was $45.75 \pm 14.16$ years. Of these patients, 11 underwent single-level lumbar microdiscectomy, whereas 1 underwent two-level lumbar microdiscectomy. Five patients underwent microdiscectomy at L4-5, and eight patients underwent microdiscectomy at L5-S1. These patients were diagnosed with spondylodiscitis at an average of $8.75 \pm 4.18$ weeks after discharge. Three (25\%) of these patients had S. aureus, 4 (33\%) had Staphylococcus epidermidis, 3 (25\%) had Escherichia coli, and 2 patients had no growth (Table 2). The patients were treated by the infection clinic, and patients whose ESR and CRP returned to normal under antibiotic treatment were discharged. The average hospital stay of these patients was $29.45 \pm 3.98$ days, and the average hospital stay of patients without spondylodiscitis was $1.99 \pm 0.81$ days, and the two groups were significantly different $(p=0.0001)$.

Methicillin resistance was not detected in any of the $S$. aureus grown in the tissue culture of three patients when the antibiotic susceptibility of the bacteria obtained from the cultures was ex- amined. In this case, it is sensitive to cefazolin given for prophylaxis. Methicillin resistance was observed in one of the $S$. epidermidis strains that were grown in four patients.

\section{DISCUSSION}

Postoperative spondylodiscitis is an unexpected condition that develops within 10 weeks after lumbar discectomy with a rate of $0.1 \%-3 \%(10,19,20)$. In percutaneous procedures performed to the disc, in addition to lumbar disc surgery, it is a serious complication since it can be seen in different situations, such as discography, chemonucleosis, and ozone therapy, and also because of its clinical course. In addition to lumbar microdiscectomy, spinal instrumentation surgery is one of the factors that increase the risk of infection. The incidence of spondylodiscitis in spinal surgeries reaches up to $35 \%$ in some studies $(21,22)$.

During diagnosis, MRI is an important and valuable tool in addition to the positivities of clinical and laboratory methods. In $M R I$, it is represented as decreased bone signal on T1-weighted MR images, increased bone signal on T2-weighted MR images, and gadolinium involvement in the end plates adjacent to the disc, disc field infection with a sensitivity between 93\% and $96 \%$ and a specificity between $92 \%$ and $97 \%(17,23)$. Decreased height of disc distance and erosive appearances in the adjacent cortical bone may be seen in advanced cases $(18,19)$. Although these show the value of the radiological study once again, these findings were found in all patients with spondylo- 
discitis. Prior to the use of MRI, technetium $99 \mathrm{~m}$ diphosphonate and gallium 67 citrate bone scintigraphy screening were considered to be a reliable test for the early detection of disc area infections. However, today, the clinic, together with increased ESR and CRP values and lumbar MRI, is sufficient for diagnosis in most patients $(18,24,25)$. In addition to MRI, computed tomography may show narrowing of the disc area and erosion of the adjacent cortical bone $(18,19)$.

Before the routine use of MRI, large series regarding spondylodiscitis have been published $(2,9,12,26)$. The incidence of disc area infection reported in these series is likely to be very low, since the sensitivity of radiography and tomography is lower than that of MRI, particularly in the detection of postoperative spondylodiscitis during the first 6 weeks after surgery (23). Most studies did not provide any information about follow-up examinations for some time $(7,17,18)$. In our study, the incidence of postoperative spondylodiscitis with single dose antibiotic prophylaxis was $1.03 \%$.

Some authors argue that percutaneous disc biopsy is effective in the diagnosis $(14,19,24,27)$. Tissue culture with biopsy obtained from the disc distance is very valuable in eradicating the pathogen causing spondylodiscitis. Although biopsy can easily be taken under tomography or fluoroscopy, the reported complication rates are low, but there is also a high false negative rate (28-30). In our study, discal biopsies were performed to all patients hospitalized with a diagnosis of spondylodiscitis, pathogens were detected, and appropriate antibiotic treatment was initiated.

Postoperative spondylodiscitis is an infection of disc distance caused by skin flora contamination. It is frequently caused by $S$. aureus and S. epidermidis (19, 24, 31). Fraser et al. (32) suggested that "aseptic" spondylodiscitis also begins with contamination of the disc area with pathogens that may infect. In these cases, the infectious process is usually self-limiting and does not lead to severe clinical symptoms, positive cultures, positive discal biopsies, and elevation of ESR and CRP values $(24,30)$. According to the literature, the incidence of postoperative spondylodiscitis increases up to $3.0 \%$ in patients who do not receive antibiotic prophylaxis $(2-4,9,11,33)$. Infection rates from $0 \%$ to $3.0 \%$ have been reported for macrosurgical approaches $(2,3,9,16,21,34)$. The rate of infection in patients undergoing microsurgical techniques ranged from $0 \%$ to $2.5 \%(5,6,16,35)$. The effect of the use of a microscope on the incidence in lumbar surgery is also a matter of debate. Kho et al. (35) reported that the infection rate increases from $0 \%$ to $2.5 \%$ after using a microscope, whereas Dauch et al. (16) observed that the infection rate decreases from $2.8 \%$ to $0.4 \%$.

There are limited studies about the effects of lumbar discectomy, spinal infections as a result of postoperative spondylodiscitis, and prophylactic intravenous antibiotic use. In some series, postoperative spondylodiscitis rate has been reported in $0 \%$ $0.5 \%$ with the use of gentamicin and first or second generation cephalosporins $(3,10)$. Horwitz and Curtin (36) focused only on wound site infections and reported a significant reduction in infection rates after lumbar disc surgery in patients using antibiotics. A single dose of cefazolin sodium antibiotic is recommended in spinal surgery cases with or without instrumentation as specified in the surgical guidelines for spinal infection prophylaxis (37). However, most surgeons tend to give antibiotics used in the postoperative period. Antibiotics used postoperatively may increase the antibiotic resistance of contaminated disc distance bacteria. In addition to antibiotic resistance as a result of irrational use of antibiotics, undesirable consequences, such as cost, side effects, and drug-drug interaction, can occur. The incidence of spondylodiscitis in $1 \%$ of our operated patients is among the values reported in the literature. Therefore, irrigation of the intervertebral disc distance with gentamicin serum, together with single dose prophylactic antibiotic given to the patients, did not result from insufficient antibiotic with respect to spectrum and duration. In our study, methicillin resistance was observed only in one patient with respect to antibiotic resistance in single dose antibiotic use. Rational use of antibiotics and antibiotic resistance are effective in the duration of treatment of spondylodiscitis.

Washing the disc distance with antibiotic serum is a common practice among surgeons. However, there are few reports on the incidence of infectious complications after lumbar discectomy (38). The incidence of disc area infection has been reported to be $0.2 \%-1.2 \%$ in cases where the cleaned cavity after discectomy is irrigated with bacitracin and/or neomycin (13). The incidence of postoperative spondylodiscitis has been reported to be between $0 \%$ and $0.5 \%$ when gentamicin and first or second generation cephalosporins are used $(3,10,26)$. In our study, gentamicin was used in irrigation fluid. Gentamicin and cephalosporin susceptibility were observed in 11 (91.6\%) patients when the susceptibility of organisms responsible for spondylodiscitis was examined. Gentamicin includes Gram-positive and Gram-negative bacteria, but may explain its effectiveness in preventing disc space infection.

In a study related to the topical applications of gentamicin, 72 patients with osteomyelitis after orthopedic surgery were placed on a collagenous sponge containing gentamicin in the infected area, and gentamicin levels in the drainage fluid were measured (31). The first 48 patients had bactericidal gentamicin levels in the drainage fluid. It is possible to reach high antibiotic levels at the site of surgery $72 \mathrm{~h}$ after surgery. In our study, based on these findings, disc area infection was approximately $1 \%$ by irrigating the disc distance with gentamicin solution, and single dose antibiotic prophylaxis could reach bactericidal gentamicin and cephalosporin levels in the first postoperative days and be effective in preventing postoperative spondylodiscitis.

Our study also has limitations. First, this is a retrospective study based on patient file records. Second, patients who were diagnosed with clinically developed spondylodiscitis were examined, and patients who were treated in subclinical or other clinics were not known. Although the patient population is not sufficient with respect to antibiotic resistance, objective results can be obtained by prospective studies. 


\section{CONCLUSION}

Although most surgeons have a tendency to maintain antibiotic prophylaxis in the postoperative period or during the hospitalization period, our study shows that a single dose prophylactic antibiotic performed during anesthesia induction does not increase the rate of spondylodiscitis compared with the medical literature.

Ethics Committee Approval: Authors declared that the research was conducted according to the principles of the World Medical Association Declaration of Helsinki "Ethical Principles for Medical Research Involving Human Subjects", (amended in October 2013).

Informed Consent: Informed consent was not taken from patients due to the retrospective nature of the study.

Peer-review: Externally peer-reviewed.

Author Contributions: Concept - F.D., M.B.Ö., H.C., A.K.; Design - F.D., M.B.Ö., H.C., A.K.; Supervision - F.D., M.B.Ö., H.C., A.K.; Resources - A.K.; Materials - A.K.; Data Collection and/or Processing - F.D., M.B.Ö., H.C., A.K.; Analysis and/or Interpretation - F.D., M.B.Ö., H.C., A.K.; Literature Search - M.B.Ö., A.K.; Writing Manuscript - F.D., M.B.Ö., H.C., A.K.; Critical Review - F.D., M.B.Ö., H.C., A.K.

Conflict of Interest: The authors have no conflict of interest to declare.

Financial Disclosure: The authors declared that this study has received no financial support.

\section{REFERENCES}

1. Andrews DW, Lavyne MH. Retrospective analysis of microsurgical and standard lumbar discectomy. Spine 1990; 15: 329-35. [CrossRef]

2. Brussatis F. Osteomyelitis following surgery of the lumbar herniated disk. Acta Neurochir 1953; 3: 209-30. [CrossRef]

3. Davis RA. A long-term outcome analysis of 984 surgically treated herniated lumbar discs. J Neurosurg 1994; 80: 415-21. [CrossRef]

4. Ford LT, Key JA. Postoperative infection of intervertebral disc space. South Med J 1955; 48: 1295-303. [CrossRef]

5. Goald HJ. Microlumbar discectomy: Follow-up of 477 patients. Microsurgery 1980; 2: 95-100. [CrossRef]

6. Kotilainen E, Valtonen S, Carlson CA. Microsurgical treatment of lumbar disc herniation: follow-up of 237 patients. Acta Neurochir 1993; 120: 143-9. [CrossRef]

7. Meinig G, Kretzschmar K, Samii M, Wallenfang F, Hülse R, Schürmann K. Spondylodiscitis-lumbar disc removal. Advances in Neurosurg 2012; 4: 55-8. [CrossRef]

8. Nolla-Sole JM, Mateo-Soria L, Rozadilla-Sacanell A, Mora-Salvador J, Valverde-Garcia J, Roig-Escofet D. Role of technetium-99m diphosphonate and gallium-67 citrate bone scanning in the early diagnosis of infectious spondylodiscitis. A comparative study. Ann Rheum Dis 1992; 51: 665-7. [CrossRef]

9. Pilgaard S. Discitis (closed space infection) following removal of lumbar intervertebral disc. J Bone Joint Surg Am 1969; 51: 713-6. [CrossRef]

10. Piotrowski WP, Krombholz MA, Mühl B. Spondylodiscitis after lumbar disk surgery. Neurosurg Rev 1994; 17: 189-93. [CrossRef]

11. Puranen J, Makela J, Lahde S. Postoperative intervertebral discitis. Acta Orthop Scand 1984; 55: 461-5. [CrossRef]

12. Seifert V, Stolke D, Vogelsang H. Die postoperative discitis intervertebralis lumbalis. Aktuelle Neurologie 1983; 10:161-166. [CrossRef]

13. Tronnier V, Schneider R, Kunz U, Albert F, Oldenkott P. Postoperative spondylodiscitis: results of a prospective study about the aetiology of spondylodiscitis after operation for lumbar disc herniation. Acta Neurochir 1992; 117: 149-52. [CrossRef]
14. Thibodeau AA. Closed space infection following removal of lumbar intervertebral disc. J Bone Joint Surg Am 1968; 50: 400-10. [CrossRef]

15. Stolke D, Sollmann WP, Seifert V. Intra-and postoperative complications in lumbar disc surgery. Spine 1989; 14: 56-9. [CrossRef]

16. Dauch WA. Infection of the intervertebral space following conventional and microsurgical operation on the herniated lumbar intervertebral disc a controlled clinical trial. Acta Neurochir 1986; 82: 43-9. [CrossRef]

17. Frank AM, Trappe AE. The role of magnetic resonance imaging (MRI) in the diagnosis of spondylodiscitis. Neurosurg Rev 1990; 13: 279-83. [CrossRef]

18. Stolke D, Seifert V, Kunz U. Postoperative lumbar intervertebral discitis. A review of a 15-year period and 7,493 operations. Z Orthop Ihre Grenzgeb 1988; 126: 666-70. [CrossRef]

19. Rawlings CE 3rd, Wilkins RH, Gallis HA, Goldner JL, Francis R. Postoperative intervertebral disc space infection. Neurosurgery 1983; 13 : 371-6. [CrossRef]

20. Dall BE, Rowe DE, Odette WG, Batts DH. Postoperative discitis. Diagnosis and management. Clin Orthop Relat Res 1987: 138-46. [CrossRef]

21. Fernand R, Lee CK. Postlaminectomy disc space infection. A review of the literature and a report of three cases. Clin Orthop Relat Res 1986: 215-8. [CrossRef]

22. Ebeling $U$, Reichenberg W, Reulen HJ. Results of microsurgical lumbar discectomy. Acta Neurochir 1986; 81: 45-52. [CrossRef]

23. Schulitz KP, Assheuer J. Discitis after procedures on the intervertebral disc. Spine 1994; 19: 1172-7. [CrossRef]

24. Fouquet B, Goupille P, Jattiot F, Cotty P, Lapierre F, Valat JP, et al. Discitis after lumbar disc surgery. Features of " aseptic" and "septic" forms. Spine 1992; 17: 356-8. [CrossRef]

25. Meyer B, Schaller K, Rohde V, Hassler W. The C-reactive protein for detection of early infections after lumbar microdiscectomy. Acta Neurochir 1995; 136: 145-50. [CrossRef]

26. Rohde V, Meyer B, Schaller C, Hassler WE. Spondylodiscitis after lumbar discectomy: incidence and a proposal for prophylaxis. Spine 1998; 23: 615-20. [CrossRef]

27. Scherbel AL, Gardner WJ. Infections involving the intervertebral disks: Diagnosis and management. JAMA 1960; 174: 370-4. [CrossRef]

28. Armstrong P, Chalmers A, Green G, Irving JD. Needle aspiration/ biopsy of the spine in suspected disc space infection. Br J Radiol 1978; 51: 333-7. [CrossRef]

29. Babu NV, Titus VT, Chittaranjan S, Abraham G, Prem H, Korula RJ. Computed tomographically guided biopsy of the spine. Spine 1994; 19: 2436-42. [CrossRef]

30. Fraser RD, Osti OL, Vernon-Roberts B. Discitis after discography. J Bone Joint Surg Am 1987; 69: 26-35. [CrossRef]

31. Gruss P, Tannenbaum H, Ott-Tannenbaum B, Megele R, Tasler J, Spohr A, et al. Die Verlaufsformen der Spondylodiszitis nach Bandscheibenoperation-zur Genese, Therapie und Prophylaxe. Neurochirurgia 1992; 35: 79-84. [CrossRef]

32. Fraser RD, Osti OL, Vernon-Roberts B. latrogenic discitis: the role of intravenous antibiotics in prevention and treatment. An experimental study. Spine 1989; 14: 1025-32. [CrossRef]

33. Bongartz $E$, Ulrich $P$, Fidler M, Bernucci C. Reoperation in the management of post-operative disc space infection. Zentralblatt für Neurochirurgie 1994; 55: 120-4.

34. Savitz M. Minilaminotomy as an alternative to laminectomy or microdiskectomy: ten years' experience. Mt Sinai J Med, New York 1991; 58: 165-167. 
35. Kho HC, Steudel WI. Comparison of the microsurgical lumbar intervertebral disk operation with the conventional technic in free sequestered intervertebral disk prolapse. A retrospective study based on 267 cases. Neurochirurgia 1986; 29: 181-5.

36. Horwitz NH, Curtin JA. Prophylactic antibiotics and wound infections following laminectomy for lumber disc herniation. J Neurosurg 1975; 43: 727-31. [CrossRef]
37. Bratzler DW, Dellinger EP, Olsen KM, Perl TM, Auwaerter PG, Bolon MK, et al. Clinical practice guidelines for antimicrobial prophylaxis in surgery. Surg Infect 2013; 14: 73-156. [CrossRef]

38. Hasselbach C. Clinic and Pharmacokinetics of Collagen Gentamicin as Adjuvant Local Therapy for Bony Infections. Unfallchirurg 1989; 92: 459-70. 